\title{
Analisis kebutuhan ruang terbuka hijau sebagai penyerap emisi gas karbon di kota dan kawasan penyangga Kota Malang
}

\author{
F. J. Miharja ${ }^{1 *}$ Husamah $^{1}$, T. Muttaqin ${ }^{2}$ \\ ${ }_{1}^{1}$ Pusat Studi Lingkungan dan Kependudukan, Universitas Muhammadiyah Malang, Malang, Indonesia \\ ${ }^{2}$ Program Studi Kehutanan, Fakultas Pertanian dan Peternakan, Universitas Muhammadiyah Malang, \\ Malang, Indonesia
}

\begin{abstract}
Abstrak
Pembangunan ruang terbuka hijau (RTH) di Malang diperlukan sebagai penyeimbang emisi gas $\mathrm{CO}_{2}$ dari aktivitas penduduk dan konsumsi bahan bakar kendaraan yang semakin tinggi. Penelitian ini bertujuan untuk menganalisis luasan $\mathrm{RTH}$ dan kemampuan serap $\mathrm{CO}_{2}$ serta besarnya emisi $\mathrm{CO}_{2}$ yang dilepaskan oleh aktivitas respirasi dan penggunaan bahan bakar minyak. Penelitian ini merupakan jenis deskriptif kuantitatif. Area pengambilan data dalam penelitian ini meliputi Kota Malang, Kota Batu dan Kabupaten Malang. Metode deskriptif digunakan untuk menggambarkan kondisi yang ada di area penelitian. Metode kuantitatif digunakan untuk menentukan luasan dan kemampuan RTH yang ada saat ini untuk menyerap $\mathrm{CO}_{2}$ dan besarnya $\mathrm{CO}_{2}$ yang dilepaskan. Total emisi gas $\mathrm{CO}_{2}$ yang dihasilkan sebesar 535.429 ton/tahun. Kebutuhan luas RTH berdasarkan jumlah emisi sebesar 9.139 ha dengan luasan area RTH yang tersedia saat ini sebesar 13,09 ha sehingga dibutuhkan 9.126 ha lahan tambahan untuk menyeimbangkan kebutuhan atas RTH.
\end{abstract}

\begin{abstract}
.
Construction of green open space (RTH) in Malang is needed as a counterweight to $\mathrm{CO}_{2}$ gas emissions from population activities and higher fuel consumption of vehicles. This study aimed to analyze the green space area and $\mathrm{CO}_{2}$ absorption capability and the amount of $\mathrm{CO}_{2}$ emissions released by respiration activities and the use of fuel oil. This research was a quantitative descriptive. Data collection areas in this study included Malang City, Batu City and Malang Regency. Descriptive method was used to describe the conditions in the research area. Quantitative methods were used to determine the extent and ability of existing green open space to absorb $\mathrm{CO}_{2}$ and the amount of $\mathrm{CO}_{2}$ released. The total $\mathrm{CO}_{2}$ emissions produced were 535,429 tons/year. Ideally, based on the total emissions, the requirement area for open green space was 9,139 ha while the currently available at 13.09 ha, so that 9,126 ha of additional land was needed to balance the need for open green space.
\end{abstract}

Keywords: green open space, area, carbon emission, Malang

Kata kunci: RTH, luas, emisi karbon, Malang

\section{PENDAHULUAN}

Malang Raya merupakan salah satu tujuan wisata dan pendidikan di Jawa Timur. Potensi sebagai daerah wisata dan pendidikan tersebut berdampak pada berkurangnya ruang terbuka hijau (RTH) dan bertambahnya bangunan fisik penunjang pariwisata dan pendidikan (Barenlitbang 2013). Hal tersebut tidak hanya terjadi di pusat kota tetapi juga menyebar hingga beberapa kawasan penyangga seperti Kota Batu dan beberapa kecamatan di Kabupaten Malang yang berbatasan dengan kota seperti Kepanjen. Menurut data BPS tahun 2016 dan 2017, jumlah hotel sebanyak 654 unit dengan jumlah wisatawan sebesar 4.713.163 orang, sedangkan jumlah mahasiswa sebanyak 92.407 orang. Jumlah wisatawan dan mahasiswa yang datang ke kawasan Malang Raya tersebut berdampak pada kepadatan wilayah dan lalu lintas, karena beririsan dengan penduduk asli di kawasan tersebut.

\footnotetext{
${ }^{*}$ Korespondensi penulis

Email: fuad.jayamiharja@gmail.com
} 
Di sisi lain, jumlah penduduk Kota Malang dan kawasan penyangga relatif tinggi. Data BPS tahun 2016 dan 2017 menunjukkan bahwa pertumbuhan penduduk per tahun sebesar 0,63\% dengan kepadatan sebesar 7.735 jiwa per $\mathrm{km}^{2}$. Jumlah tersebut cenderung mengalami peningkatan setiap tahun. Pertumbuhan jumlah penduduk merupakan salah satu faktor penyumbang emisi gas karbondioksida $\left(\mathrm{CO}_{2}\right)$. Emisi tersebut dihasilkan dari aktivitas alami dan aktivitas penduduk (antropogenik) seperti emisi hasil konsumsi bahan bakar kendaraan dan aktivitas pernafasan. Tingginya kepadatan kota merupakan salah satu sumber permasalahan yang menimbulkan kemacetan dan buruknya kualitas udara karena emisi $\mathrm{CO}_{2}$ yang dihasilkan kendaraan bermotor (Lussetyowati 2011; Muharama 2016; Samiaji 2011). Emisi yang dihasilkan dari aktivitas manusia cenderung memiliki potensi kerusakan lingkungan yang lebih tinggi, karena konsentrasi emisi gas yang lebih tinggi daripada emisi yang dihasilkan dari secara alami (Roshintha dan Mangkoedihadjo 2016).

Di sisi lain, jumlah kendaraan bermotor di wilayah Malang dalam rentang waktu 2015 hingga 2016 terus mengalami perkembangan. Jumlah kendaraan bermotor yang terdaftar sebesar 563.125 unit. Sepeda motor mendominasi jumlah kendaraan bermotor sebesar $75-80 \%$, sedangkan sisanya adalah mobil dan kendaraan besar lainnya (Arifin 2018). Penelitian Endes (2007; 2011); Kusumaningrum (2008) memaparkan bahwa tingginya konsumsi bahan bakar dari aktivitas transportasi meningkatkan konsentrasi ambien gas $\mathrm{CO}_{2}$ yang menimbulkan pemanasan global. Hal tersebut menguatkan hasil beberapa penelitian lain yang menyatakan bahwa $\mathrm{CO}_{2}$ merupakan substansi gas yang paling berkontribusi terhadap gejala pemanasan global hingga lebih dari 75\% (Moediarta dan Stalker 2007). Lebih lanjut, pemanasan global berpotensi besar menyebabkan perubahan iklim yang berdampak pada kehidupan manusia (Puslitbang Perubahan Iklim dan Kebijakan 2010; Nursanti dan Swari 2013). Oleh karena itu, konsentrasi gas $\mathrm{CO}_{2}$ di udara harus dikendalikan agar tidak terus bertambah naik dengan membangun ruang terbuka hijau (Endes 2011).

Di lain pihak, untuk mengatasi kondisi tersebut, pembangunan ruang terbuka hijau (RTH) telah dilakukan di beberapa wilayah. Keberadaan RTH tersebut berperan penting sebagai penyeimbang antara kawasan terbangun dengan kebutuhan terhadap ruang terbuka sesuai dengan peraturan pemerintah terkait ketersediaan minimal 30\% ruang hijau di wilayah perkotaan (Hayat 2014; Mulyadin dan Gusti 2015). RTH sebagai kawasan penyerap emisi berperan dalam mengkonversi gas $\mathrm{CO}_{2}$ menjadi $\mathrm{O}_{2}$. Lukita et al. (2015) dan Suryaningsih et al. (2015) menyatakan bahwa karakteristik RTH dan vegetasi di dalamnya merupakan aspek penting bagi kepentingan masyarakat dalam penyerapan emisi $\mathrm{CO}_{2}$. Peran vegetasi pada $\mathrm{RTH}$ sebagai penyerap $\mathrm{CO}_{2}$ di atmosfer menjadi bagian penting untuk mengatasi pencemaran udara, khususnya pemanasan 
global. Keberadaan vegetasi yang mampu menyerap $\mathrm{CO}_{2}$ dalam suatu lanskap diperlukan untuk menciptakan masyarakat rendah karbon (low carbon society) (Adinugroho et al. 2013).

Namun demikian, belum ada kajian terhadap kebutuhan RTH di Kota Malang dan kawasan penyangga terkait melalui pendekatan jumlah penduduk dan jumlah emisi $\mathrm{CO}_{2}$ yang dihasilkan melalui aktivitas penduduk. Penelitian ini bertujuan untuk mendapatkan gambaran ketersediaan RTH serta kebutuhan pengembangan untuk mewujudkan keseimbangan dengan emisi yang dihasilkan $\mathrm{CO}_{2}$. Hasil dari penelitian ini dapat dijadikan rujukan dalam Implementasi Rencana Tata Ruang Wilayah (RTRW) program pembangunan pemerintah dengan tetap memperhatikan proporsi antara bangunan dan RTH serta penelitian lebih lanjut.

\section{METODOLOGI}

\subsection{Lokasi kajian dan waktu penelitian}

Penelitian ini dilakukan pada beberapa titik di Kota Malang, Kota Batu, dan Kabupaten Malang. Area pengamatan di Kota Malang meliputi Alun-alun Kota Malang, Hutan Kota Malabar, Areal Taman Simpang Balapan, Areal Taman Ijen Boulevard, Balai Kota, Taman Trunojoyo, Taman Kunang-kunang; wilayah Kota Batu meliputi yaitu Alun-alun Kota Batu dan Hutan Kota Batu; serta di Kabupaten Malang meliputi area Stadion Kanjuruhan (Gambar 1).

Proses pengumpulan data dilakukan pada bulan November-Desember 2016. Data pada penelitian ini meliputi data primer dan data sekunder. Data primer meliputi pengukuran luas area dan vegetasi di dalamnya. Data sekunder meliputi informasi jumlah penduduk serta konsumsi bahan bakar.

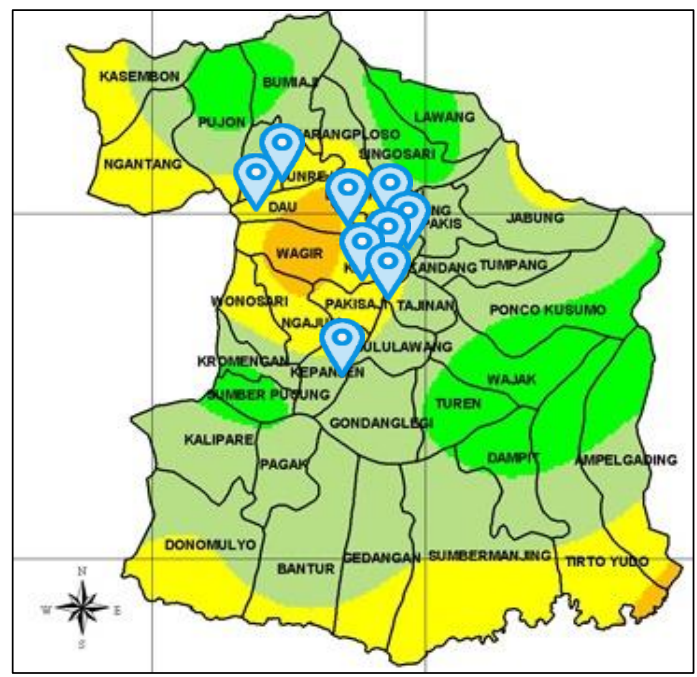

Gambar 1. Cakupan area penelitian. 


\subsection{Prosedur analisis data}

Analisis data meliputi analisis emisi $\mathrm{CO}_{2}$ hasil dari konsumsi bahan bakar dan pernafasan manusia, analisis daya serap karbon atas vegetasi yang diamati di lapangan, dan analisis kebutuhan luas ruang terbuka hijau. Perhitungan analisis tersebut sebagai berikut.

1. Analisis emisi $\mathrm{CO}_{2}$

a) Emisi hasil konsumsi bahan bakar

Faktor emisi untuk bahan bakar bensin sebesar 2,3 $\mathrm{g} \mathrm{CO}_{2}$ /liter dan solar sebesar 2,7 $\mathrm{g} \mathrm{CO}_{2}$ /liter (DEFRA 2006). Analisis dilakukan berdasarkan kuota konsumsi bahan bakar minyak Kota Malang pada Tahun 2014. Faktor emisi $\mathrm{CO}_{2}$ seperti dijabarkan pada Tabel 1. Perhitungannya sebagai berikut:

$$
B=(b \times j b)+(s \times j s)
$$

Keterangan:

$\mathrm{B}=$ Total emisi $\mathrm{CO}_{2}$ dari bahan bakar (ton/tahun)

$\mathrm{b} \quad=$ Nilai emisi bensin ( $\mathrm{g} /$ liter)

$\mathrm{jb}=$ Jumlah konsumsi nilai bensin (liter/tahun)

$\mathrm{s} \quad=$ Nilai emisi solar (g/liter)

js = Jumlah konsumsi nilai solar (liter/tahun)

Tabel 1. Faktor emisi $\mathrm{CO}_{2}$ dari konsumsi bahan bakar.

\begin{tabular}{clc}
\hline No & Jenis Bahan Bakar & $\mathrm{gCO}_{2} /$ liter \\
\hline 1 & Gas Alam & 0,19 \\
2 & Minyak Diesel & 0,25 \\
3 & Bensin & 0,24 \\
4 & Bahan Bakar Berat & 0,26 \\
\hline & Rata-Rata & 0,24 \\
\hline
\end{tabular}

b) Emisi Hasil Pernafasan Manusia

$\mathrm{CO}_{2}$ yang dihasilkan dalam proses pernafasan manusia adalah 0.3456 ton $\mathrm{CO}_{2} /$ jiwa/tahun (Grey 1996). Perhitungan emisi $\mathrm{CO}_{2}$ yang dihasilkan penduduk mengikuti perhitungan berikut:

$$
\mathrm{P}=\mathrm{J}_{\mathrm{p}} \times \mathrm{C}_{\text {manusia }}
$$

Keterangan:

$$
\begin{array}{ll}
\mathrm{P} & =\text { Total emisi } \mathrm{CO}_{2} \\
\mathrm{JP} & =\text { Jumlah penduduk (jiwa) } \\
\mathrm{C}_{\text {manusia }} & =\text { Jumlah } \mathrm{CO}_{2} \text { yang dihasilkan manusia }(0,3456 \text { ton/jiwa/tahun) }
\end{array}
$$

2. Analisis serapan $\mathrm{CO}_{2}$ vegetasi

Analisis serapan $\mathrm{CO}_{2}$ pada vegetasi yang ada pada RTH Malang Raya dilakukan dengan mengalikan luas area dengan nilai penyerapan emisi $\mathrm{CO}_{2}$ 
rata-rata dari vegetasi ruang terbuka dalam kota sebesar 58,2576 ton/tahun/ha (Tinambunan 2015).

3. Analisis kebutuhan luas ruang terbuka hijau

Kebutuhan optimum RTH berdasarkan daya serap $\mathrm{CO}_{2}$ diperoleh berdasarkan kemampuan serapan $\mathrm{CO}_{2}$ vegetasi yang ada didalamnya. Analisis yang digunakan dengan menghitung kebutuhan RTH dan membandingkannya dengan luasan RTH saat ini. Kebutuhan RTH diperoleh dari jumlah emisi $\mathrm{CO}_{2}$ dibagi dengan kemampuan RTH dalam menyerap $\mathrm{CO}_{2}$ (Mulyadin dan Gusti 2015; Tinambunan 2015). Perhitungannya adalah sebagai berikut:

$$
\mathrm{L}_{1}=\frac{\mathrm{B}+\mathrm{P}}{\mathrm{K}}
$$

Keterangan:

L1 = Kebutuhan RTH (ha)

$\mathrm{B}=$ Total emisi $\mathrm{CO}_{2}$ dari konsumsi bahan bakar (ton/tahun)

$\mathrm{P} \quad=$ Total emisi $\mathrm{CO}_{2}$ dari penduduk (ton/tahun)

$\mathrm{K}=$ Kemampuan nilai serapan total emisi $\mathrm{CO}_{2}$ dari oleh pohon sebesar 58,2576 (ton $\mathrm{CO}_{2} /$ tahun/ha)

Setelah mendapat nilai kebutuhan RTH (L), maka jumlah penambahan luasan RTH yang dibutuhkan dapat diperoleh dengan perhitungan:

$$
\mathrm{L}=\mathrm{L}_{1}-\mathrm{L}_{0}
$$

Keterangan:

$\mathrm{L} \quad$ = Penambahan RTH yang dibutuhkan (ha)

$\mathrm{L}_{1} \quad=$ Kebutuhan RTH (ha)

$\mathrm{L}_{0} \quad=$ Luas RTH saat ini (ha)

\section{HASIL DAN PEMBAHASAN}

\subsection{Emisi hasil pernafasan manusia}

Manusia sebagai makhluk hidup melakukan respirasi selama masa hidupnya. Proses respirasi menghasilkan produk berupa gas $\mathrm{CO}_{2}$ yang akan dikembalikan ke udara bebas. Semakin banyak jumlah penduduk maka berbanding lurus dengan jumlah gas $\mathrm{CO}_{2}$ yang dihasilkan. Berdasarkan data BPS (2016) jumlah penduduk di Kota Malang dan beberapa wilayah penyangga mengalami peningkatan sebesar $0,63-0,75 \%$ setiap tahun. Jumlah penduduk dalam 3 tahun terakhir dijabarkan seperti pada Tabel 2. Berdasarkan hasil perhitungan tersebut, jumlah penduduk pada tahun 2017 adalah jumlah tertinggi dengan total penduduk sebanyak 1.173.366 jiwa, sedangkan rata-rata jumlah penduduk selama 3 tahun terakhir sebesar 1.165.956 jiwa.

Bila asumsi gas $\mathrm{CO}_{2}$ yang dihasilkan oleh aktivitas penduduk adalah sama sebesar 0,3456 ton $\mathrm{CO}_{2}$ /jiwa/tahun (Mulyadin dan Gusti 2015), maka rata-rata 
total emisi gas $\mathrm{CO}_{2}$ yang dihasilkan dari proses respirasi penduduk sebesar 402.955 ton/tahun. Hasil ini diperkirakan masih akan meningkat karena proyeksi pertumbuhan jumlah penduduk di Kota Malang pada 2020 sebesar 874.890 jiwa serta laju pertumbuhan penduduk sebesar 1-2\% setiap tahun (BPS 2016; 2017). Selain itu, laju pertambahan jumlah wisatawan yang berkunjung ke wilayah Malang Raya diprediksi akan meningkat seiring dengan pengelolaan konsep pariwisata terintegrasi diantara Kota Malang, Kota Batu dan Kabupaten Malang. Disamping itu, peningkatan jumlah mahasiswa di wilayah Malang juga semakin tinggi sejalan dengan meningkatnya mutu perguruan tinggi.

Tabel 2. Jumlah penduduk Kota Malang dan kawasan penyangga.

\begin{tabular}{cllrrr}
\hline \multirow{2}{*}{ No } & \multicolumn{1}{c}{ Kota/ } & \multirow{2}{*}{ Kecamatan } & \multicolumn{2}{c}{ Jumlah Penduduk (jiwa) } \\
\cline { 4 - 6 } & \multicolumn{1}{c}{ Kabupaten } & Kedungkandang & 186.068 & 188.175 & 190.274 \\
1 & Kota Malang & Sukun & 190.053 & 191.513 & 192.951 \\
2 & Kota Malang & Klojen & 104.127 & 103.637 & 103.129 \\
3 & Kota Malang & Blimbing & 177.729 & 178.564 & 179.368 \\
4 & Kota Malang & Lowokwaru & 193.321 & 194.521 & 195.692 \\
5 & Kota Malang & Batu & 93.227 & 94.132 & 94.966 \\
6 & Kota Batu & Junrejo & 49.505 & 50.079 & 50.617 \\
7 & Kota Batu & Bumiaji & 57.753 & 58.108 & 58.414 \\
8 & Kota Batu & Kepanjen & 106.668 & 107.323 & 107.955 \\
9 & Kabupaten Malang & $\mathbf{1 . 1 5 8 . 4 5 1}$ & $\mathbf{1 . 1 6 6 . 0 5 2}$ & $\mathbf{1 . 1 7 3 . 3 6 6}$ \\
\hline \multicolumn{3}{c}{ Total } & & & $\mathbf{1 . 1 6 5 . 9 5 6}$ \\
\hline \multicolumn{2}{c}{ Rata-rata } \\
\hline
\end{tabular}

\subsection{Konsumsi Bahan Bakar}

Salah satu sumber emisi gas $\mathrm{CO}_{2}$ adalah hasil pembakaran dari bahan bakar fosil yang digunakan oleh penduduk. Bahan bakar yang dikonsumsi meliputi premium, pertalite dan pertamax (untuk kendaraan bermesin bensin), serta solar (untuk kendaraan bermesin diesel). Nilai emisi yang dihasilkan oleh bahan bakar tersebut berbeda-beda bergantung pada nilai oktan.

Konsumsi bahan bakar kendaraan bermotor di wilayah Malang pada tahun 2018 sebesar $450 \mathrm{kl} /$ hari untuk bahan bakar jenis premium, $900 \mathrm{kl} /$ hari untuk jenis pertalite, pertamax sebanyak $450 \mathrm{kl} /$ hari dan dexlite sebesar $80 \mathrm{kl} / \mathrm{hari}$ (Tabel 3). Menurut data (DEFRA 2006) nilai emisi bahan bakar bensin sebesar 2,31 g/l dan solar sebesar 2,63 g/l. Dengan demikian, polusi udara berupa gas $\mathrm{CO}_{2}$ yang dihasilkan dari konsumsi bahan bakar mencapai 129.474 ton/tahun.

Tabel 3. Jumlah konsumsi bahan bakar di wilayah Malang berdasarkan jenisnya.

\begin{tabular}{|c|c|c|c|}
\hline No & Jenis Bahan Bakar & $\mathrm{kl} / \mathrm{hari}$ & $\mathrm{kl} /$ tahun \\
\hline 1 & Premium & 450 & 13500 \\
\hline 2 & Pertalite & 900 & 27000 \\
\hline 3 & Pertamax & 450 & 13500 \\
\hline 4 & Dexlite & 60 & 1800 \\
\hline
\end{tabular}




\subsection{Serapan $\mathrm{CO}_{2}$ Vegetasi}

Vegetasi yang tumbuh pada RTH memiliki peran vital sebagai penyerap emisi gas $\mathrm{CO}_{2}$ di udara. Menurut Tinambunan (2015), suatu area vegetasi dapat menyerap emisi $\mathrm{CO}_{2}$ sebesar 58,2576 ton/tahun/ha. Analisis daya serap areal vegetasi disajikan dalam Tabel 4. Hasil analisis menunjukkan bahwa luas total RTH di Kota Malang dan kawasan penyangga sebesar 13,09 ha, dengan total emisi gas $\mathrm{CO}_{2}$ yang mampu diserap vegetasi sebesar 762,589 ton $\mathrm{CO}_{2} /$ tahun.

Tabel 4. Analisis daya serap gas $\mathrm{CO}_{2}$ berdasarkan luas area.

\begin{tabular}{clcc}
\hline No & \multicolumn{1}{c}{ Area } & Luas (ha) & $\begin{array}{c}\text { Penyerapan } \mathrm{CO}_{2} \\
\text { (ton/tahun) }\end{array}$ \\
\hline 1 & Alun-alun Kota Batu & 0,87 & 50,68 \\
2 & Alun-alun Kota Malang & 0,15 & 8,74 \\
3 & Stadion Kanjuruhan & 3,50 & 203,90 \\
4 & Ijen Boulevard & 2,69 & 156,71 \\
5 & Balai Kota & 1,19 & 69,33 \\
6 & Trunojoyo & 0,58 & 33,79 \\
7 & Hutan Kota Batu & 1,24 & 72,239 \\
8 & Taman Kunang-kunang & 1,19 & 69,33 \\
9 & Hutan Kota Malabar & 1,68 & 97,87 \\
\hline \multicolumn{2}{r}{ Total } & $\mathbf{1 3 , 0 9}$ & $\mathbf{7 6 2 , 5 8 9}$ \\
\hline
\end{tabular}

\subsection{Analisis Kebutuhan Luas Ruang Terbuka Hijau}

Jumlah penduduk yang tinggi memiliki korelasi terhadap aktivitas yang dilakukannya. Dalam hal ini, konsumsi bahan bakar dan produk respirasi memberi dampak terhadap jumlah $\mathrm{CO}_{2}$ yang dihasilkan, sehingga berpotensi menimbulkan polusi udara. Polusi merupakan hasil dari semakin tingginya jumlah $\mathrm{CO}_{2}$ yang tidak diimbangi dengan ketersediaan lahan terbuka sehingga tidak mampu menampung banyaknya gas yang dihasilkan.

Berdasarkan hasil analisis, total emisi $\mathrm{CO}_{2}$ dari konsumsi bahan bakar dan aktivitas respirasi penduduk sebesar 532.429 ton $\mathrm{CO}_{2}$ /tahun dengan kemampuan penyerapan $\mathrm{CO}_{2}$ berdasarkan ketersediaan $\mathrm{RTH}$ yang sudah ada sebesar 762,589 ton/tahun. Bila kemampuan penyerapan $\mathrm{CO}_{2}$ sebesar 58,2576 ton/tahun/ha, maka luas lahan yang dibutuhkan oleh Kota Malang dan kawasan penyangga untuk menyeimbangkan kebutuhan atas RTH sebesar 9.126,12 ha (Tabel 5).

Tabel 5. Analisis kebutuhan luas ruang terbuka hijau.

\begin{tabular}{ccccc}
\hline $\begin{array}{c}\text { Total Emisi } \mathrm{CO}_{2} \\
\text { (ton/tahun) }\end{array}$ & $\begin{array}{c}\text { Kemampuan } \\
\text { Penyerapan } \mathrm{CO}_{2} \\
\text { (ton/tahun/ha) }\end{array}$ & $\begin{array}{c}\text { Kebutuhan } \\
\text { RTH } \\
\text { Berdasarkan } \\
\text { Emisi CO } \text { (ha) }\end{array}$ & $\begin{array}{c}\text { Luasan } \\
\text { RTH Saat } \\
\text { Ini } \\
\text { (ha) }\end{array}$ & $\begin{array}{c}\text { Selisih } \\
\text { (ha) }\end{array}$ \\
\hline 532.429 & 58,2576 & $9.139,21$ & 13,09 & $9.126,12$ \\
\hline
\end{tabular}


Keberadaan RTH merupakan faktor penting dalam menjaga keseimbangan ekosistem di wilayah perkotaan. Keseimbangan ekologi di wilayah kota harus menjadi pertimbangan sebagai penahan pembangunan fisik agar tidak terjadi destruksi lahan atau konversi lahan produktif. Langkah yang dapat ditempuh dalam rangka menyediakan ruang terbuka untuk penyerapan emisi karbon adalah mengambil alih kepemilikan lahan kering sebesar 8.988,25 ha untuk dialihfungsikan menjadi ruang terbuka hijau (BPS 2016). Tingginya nilai emisi $\mathrm{CO}_{2}$ dapat terus meningkat bila tidak segera diimbangi dengan perluasan lahan terbuka hijau sebagai area serapan. Keefektifan penyerapan emisi $\mathrm{CO}_{2}$ dapat ditingkatkan dengan pemilihan tanaman dengan daya serap yang tinggi seperti angsana dan trembesi. Jika kebutuhan terhadap lahan terbuka dan tanaman dengan daya serap terpenuhi, maka emisi $\mathrm{CO}_{2}$ dapat ditekan. Lebih jauh, bila konsep ini diterapkan di semua kota maka pemanasan global data diatasi dengan baik (Endes 2011).

\section{KESIMPULAN DAN SARAN}

Berdasarkan hasil yang diperoleh dari penelitian ini diketahui bahwa luas RTH di Kota Malang dan kawasan penyangga kota yang tersedia saat ini sebesar 13,09 ha masih belum seimbang dengan jumlah emisi yang dihasilkan. Total emisi $\mathrm{CO}_{2}$ yang dihasilkan sebesar 532.429 ton/tahun, sehingga perlu Penambahan luas RTH sebesar 9.126,12 ha untuk menyeimbangkan jumlah emisi dan kemampuan serapan gas $\mathrm{CO}_{2}$. Hasil penelitian ini merekomendasikan perlu adanya upaya strategis untuk menambah luas RTH sebagai area serapan gas $\mathrm{CO}_{2}$ serta dengan melakukan intensifikasi penyerapan gas dengan menambahkan tumbuh-tumbuhan yang memiliki kemampuan serap karbon yang tinggi seperti angsana dan trembesi untuk meningkatkan kemampuan penyerapan dari RTH yang telah tersedia.

\section{DAFTAR PUSTAKA}

Adinugroho WC, Indrawan A, Supriyanto S dan Arifin HS. 2013. Kontribusi sistem agroforestri terhadap cadangan karbon di Hulu DAS Kali Bekasi. Jurnal Hutan Tropis 1(3):242-249.

Arifin Z. 2018. Jumlah kendaraan hampir separuh penduduk kota malangregional [internet]. Tersedia di: https://www.liputan6.com/regional/read /3337501/jumlah-kendaraan-hampir-separuh-penduduk-kota-malang.

[Barenlitbang] Badan Perencanaan, Penelitian, dan Pengembangan. 2013. Rencana pembangunan jangka menengah Kota Malang 2013-2018. Barenlitbang Kota Malang. Malang.

[BPS] Badan Pusat Statistik. 2016. Kota Malang dalam angka 2016. BPS Kota Malang. Malang. 
[BPS] Badan Pusat Statistik. 2017. Batu dalam angka. BPS Kota Batu. Batu. [DEFRA] Department for Environment, Food and Rural Affairs. 2006. Environmental key performance indicators. DEFRA. London.

Endes DN. 2007. Analisis kebutuhan luasan hutan kota sebagai sink gas $\mathrm{CO}_{2}$ antropogenik dari bahan bakar minyak dan gas di Kota Bogor dengan pendekatan sistem dinamik [Disertasi]. Program Studi Ilmu Pengetahuan Kehutanan, Institut Pertanian Bogor. Bogor.

Endes DN. 2011. Kebutuhan luasan areal hutan kota sebagai rosot (sink) gas $\mathrm{CO}_{2}$ untuk mengantisipasi penurunan luasan ruang terbuka hijau di Kota Bogor. Forum Geografi 25(2):164-177.

Grey GW. 1996. The urban forest: comprehensive management. John Wiley. New York.

Hayat H. 2014. Implementasi kebijakan penataan ruang terbuka hijau. Jurnal Ilmu Administrasi Negara 13(1):43-56.

Kusumaningrum N. 2008. Potensi tanaman dalam menyerap $\mathrm{CO}_{2}$ dan $\mathrm{CO}$ untuk mengurangi dampak pemanasan global. Jurnal Permukiman 3(2):96-105.

Lukita CW, Hermana J dan Boedisantoso R. 2015. Inventarisasi serapan karbon oleh ruang terbuka hijau di Kota Malang, Jawa Timur [Prosiding]. Prosiding Seminar Nasional Manajemen Teknologi XXII 1-7.

Lussetyowati T. 2011. Analisa penyediaan ruang terbuka hijau perkotaan, studi kasus Kota Martapura [Prosiding]. Prosiding Seminar Nasional AVoER Ke3 195-207.

[Puslitbang] Pusat Penelitian dan Pengembangan Perubahan Iklim dan Kebijakan. 2010. Cadangan karbon pada berbagai tipe hutan dan jenis tanaman di Indonesia. Puslitbang Perubahan Iklim dan Kebijakan, Kementerian Kehutanan. Bogor.

Moediarta R dan Stalker P. 2007. Sisi lain perubahan iklim. UNDP Indonesia. Jakarta.

Muharama H. 2016. Kepadatan penduduk menyebabkan kemacetan di Kota Malang [internet]. Tersedia di: https://www.kompasiana.com/ hartinimuharama/58568bdae422bd4a0afd3a76/kepadatan-pendudukmenyebabkan-kemacetan-di-kota-malang.

Mulyadin RM dan Gusti REP. 2015. Analisis kebutuhan luasan area hijau berdasarkan daya serap $\mathrm{CO}_{2}$ di Kabupaten Karanganyar Jawa Tengah. Jurnal Penelitian Sosial Dan Ekonomi Kehutanan 10(4):264-273.

Nursanti N dan Swari EI. 2013. Potensi keanekaragaman hayati, iklim mikro dan serapan karbon pada ruang terbuka hijau Kampus Mendalo Universitas Jambi. Bioplante 2(2):101-112.

Roshintha RR dan Mangkoedihadjo S. 2016. Analisis kecukupan ruang terbuka hijau sebagai penyerap emisi gas karbon dioksida $\left(\mathrm{CO}_{2}\right)$ pada kawasan 
Kampus ITS Sukolilo, Surabaya. Jurnal Teknik ITS 5(2).

Samiaji T. 2011. Gas $\mathrm{CO}_{2}$ di wilayah Indonesia. Berita Dirgantara 12(2):68-75.

Suryaningsih L, Haji ATS dan Wirosoedarmo R. 2015. Analisis spasial defisiensi ruang terbuka hijau (RTH) di Kota Mojokerto. Jurnal Sumberdaya Alam dan Lingkungan 1:1-10.

Tinambunan RS. 2015. Analisis kebutuhan ruang terbuka hijau di Kota Pekanbaru [Tesis]. Pengelolaan Sumber Daya Alam dan Lingkungan, Sekolah Pascasarjana, Institut Pertanian Bogor. Bogor. 